\title{
Article
}

\section{Antitumor effects of a recombinant baculovirus displaying anti-HER2 scFv expressing Apoptin in HER2 positive SK- BR-3 breast cancer cells}

Meysami, Parisa, Rezaei, Farhad, Marashi, Sayed Mahdi, Amiri, Mohammad Mehdi, Bakker, Emyr and Mokhtari-Azad, Tálat

Available at http://clok.uclan.ac.uk/26524/

Meysami, Parisa, Rezaei, Farhad, Marashi, Sayed Mahdi, Amiri, Mohammad Mehdi, Bakker, Emyr ORCID: 0000-0002-0091-1029 and Mokhtari-Azad, Talat (2019) Antitumor effects of a recombinant baculovirus displaying anti-HER2 SCFV expressing Apoptin in HER2 positive SK-BR-3 breast cancer cells. Future Virology, 14 (3). ISSN 1746-0794

It is advisable to refer to the publisher's version if you intend to cite from the work. http://dx.doi.org/10.2217/fvl-2018-0187

For more information about UCLan's research in this area go to http://www.uclan.ac.uk/researchgroups/ and search for <name of research Group>.

For information about Research generally at UCLan please go to http://www.uclan.ac.uk/research/

All outputs in CLoK are protected by Intellectual Property Rights law, including Copyright law. Copyright, IPR and Moral Rights for the works on this site are retained by the individual authors and/or other copyright owners. Terms and conditions for use of this material are defined in the policies page. 


\title{
Antitumor effects of a recombinant Baculovirus displaying anti-HER2 scFv expressing Apoptin in HER2 positive SK-BR-3 breast cancer cells
}

\author{
Parisa Meysami ${ }^{1}$, Farhad Rezaei ${ }^{1}$, Sayed Mahdi Marashi', Mohammad Mehdi Amiri ${ }^{2}$, Emyr $^{1}$ \\ Bakker $^{3}$, Talat Mokhtari-Azad ${ }^{1}$ \\ 1. Department of Virology, School of Public Health, Tehran University of Medical Sciences, Tehran, 1471613151, Iran \\ 2. Department of Immunology, School of Public Health, Tehran University of Medical Sciences, Tehran, 1471613151, \\ Iran \\ 3. School of Medicine, University of Central Lancashire, Preston, UK; ebakker@uclan.ac.uk (E.B.)
}

Correspondence to:

Talat Mokhtari-Azad, mokhtari@hotmail.com

Farhad Rezaei, rezaei@tums.ac.ir 


\section{A B S T R A C T}

Aim: Since HER2-targeted therapies have shown clinical benefit in breast cancer, in the present study recombinant baculovirus (BV) displaying anti-HER2 $\mathrm{scFv}$ expressing Apoptin was generated. Methods: The binding specificity and surface display of anti-HER2 $\mathrm{scFv}$ were evaluated using ELISA and electron microscopy, respectively. The targeting properties and cytotoxic effect on breast cancer cells determined by fluorescence microscopy and MTT assays. Results: The results demonstrated that recombinant BV could specifically bind to HER2-overexpressing SK-BR-3 cells but not to the HER2 negative MCF-7 cells and reduced the viability of SK-BR-3 cells by expressing Apoptin. Conclusion: These results suggest that the antitumor effect of Apoptin in combination with HER2 targeting of this recombinant BV makes it a promising vector in targeted cancer therapy.

Keywords: Apoptin, breast cancer, baculovirus surface display, anti-HER2 scFv 


\section{Introduction}

Breast cancer is the most common type of cancer in women and its prevalence has increased by approximately $40 \%$ worldwide during the past 25 years[1]. Although conventional therapies in breast cancer such as surgery, chemotherapy, radiotherapy and hormone therapy treatments-are beneficial for suppressing the tumor growth, their low tumor selectivity and high toxicity ef these treatments highlights a need for the research and development of improved, cancer-selective therapeutics. Targeted therapy due to the minimizing the side effects has become increasingly interesting for cancer treatments [1-3].

Human epidermal growth factor receptor-2 (HER2) is a transmembrane tyrosine kinase receptor which is highly expressed in $25-30 \%$ of all breast cancer cases and is associated with poor prognosis and aggressive tumor phenotypes. HER 2 overexpression and its extracellular domain accessibility make it a valuable target for receptor-mediated, targeted drug delivery systems in cancer therapy [4]. The humanized monoclonal antibody trastuzumab (Herceptin ${ }^{\mathrm{TM}}$ ), which is used for treatment of cancer cells overexpressing HER2, is one of the most promising drugs in breast cancer therapy. Despite increases in cell death via various mechanisms and prolonged survival of patients with HER2overexpressing breast cancers by treated with trastuzumab, it showed moderate potency, toxic sideeffects and drug resistance in $66-88 \%$ of patients. Therefore, additional therapies are needed $[5,6]$.

Gene therapy has provided potential treatments for a number of different diseases which are difficult to treat by conventional therapy. Among different systems in gene therapy, viral vectors have become important tools to introduce therapeutic genes into the cells. Baculoviral vectors derived from the insect Autographa californica multiple nucleopolyhedrovirus (AcMNPV) virus of the baculovirus (BV) family which carries mammalian cell active promoters has shown to be able to mediate gene transfer to a broad range of mammalian cell types. Although baculovirus vectors have not yet been used as a gene therapy agents in clinical practice, they have demonstrated promising potential in various preclinical studies for a variety of therapeutic applications including cancer treatment, tissue engineering, and vaccination [7]. In contrast to human viral vectors such as retroviruses, adenoviruses, and adeno-associated viruses, baculoviruses cannot replicate in mammalian cells and there is no detectable immune responses to BV in humans [7, 8]. Furthermore, their large cloning capacity (38 $\mathrm{kb}$ ), easy manipulation, high recombinant viral titers and minimal cytotoxicity, all make this vector highly attractive for cancer gene therapy [9-11]. Also, baculovirus display technology has been used for presentation of foreign proteins on the recombinant BV, GP64 envelope glycoprotein for different therapeutic applications. For instance, a BV vector displaying $\mathrm{scFv}$ (single-chain variable domain fragment) specific CEA (carcinoembryonic antigen) to GP64 demonstrated binding specificity to CEA-expressing cells. However, the fusion to GP64 restricts the display to the poles of the virions, therefore other strategies for BVs display have been proposed [12] [13].

ScFvs comprised of the variable heavy domain $(\mathrm{VH})$ and the variable light domain $(\mathrm{VL})$ are the smallest functional antigen-binding domain of an antibody [4, 14]. Due to their low cost, easy production, faster blood clearance and better tumor penetration in comparison with full-length antibodies, they have many advantages as potential therapeutics for several diseases, including HIV, cancer and neurodegenerative diseases. Therefore, they are more favourable for targeting specific markers on tumor cells by viral vector in drug delivery systems $[15,16]$.

Combination therapy by the monoclonal antibody which mediated targeting of cancer cells with an optimized cytotoxic effector is a promising strategy for treatment of HER2-positive tumors, due to the reducing the damage to normal tissues [17].

Modulation of apoptosis is a powerful tool in cancer therapy. Apoptin (VP3) is an anti-cancer protein derived from chicken anemia virus (CAV) that induces the selective death in different cancer cell lines but not in normal cells. Apoptin tumor_-specificity is associated with its ability to localize in the nuclei of transforming cells, whereas it is mainly found in the cytoplasm of normal cells [14, 18-20]. 
However, the precise mechanisms of Apoptin-induced cell death remainsremain unclear, though it has been proposed that Apoptin induces apoptosis by phosphorylation atwhen phosphorylated at threonine 108 of by Apoptin-specific kinases in tumor cells[21]. Moreover, phosphorylated Nur77, a nuclear orphan receptor, can be relocated from the nucleus to the cytoplasm upon transient expression of Apoptin and it regulates the binding of Nur77 to the anti-apoptotic protein Bcl-2 which triggers the p53-independent mitochondrial death pathway [22]. Numerous studies have reported that recombinant adenoviruses, poxviruses and parvoviruses expressing Apoptin had significant antitumor activity in vivo [23]. Therefore, these advantages make Apoptin an attractive agent for selective anticancer therapy.

Baculoviruses expressing Apoptin have been studied in human hepatocarcinoma cells (HepG2) [9], but there is no study on the baculovirus expressing Apoptin in breast cancer cells. Therefore, we aimedthe aim was to develop a dual function recombinant baculovirus displaying anti-HER2 scFv expressing Apoptin which specifically targets HER2-positive breast cancer cell lines by anti-HER2 scFv which also displays a cytotoxic effect via Apoptin.

\section{Materials and methodsMethods}

\section{- Cell lines and cultures}

SK-BR-3 (high HER-2 expression), MCF-7 (low HER-2 expression) CHO (Chinese hamster ovary cells) and HEK-293 (human embryonic kidney cells) cell lines were obtained from the Iranian Biological Resources Centre (IBRC) [24]. Cells were grown at $37{ }^{\circ} \mathrm{C}$ with $5 \% \mathrm{CO}_{2}$ in Dulbecco Modified Eagle Medium (DMEM) (Gibco, USA) containing 10\% fetal bovine serum (Gibco, USA), $1 \%$ L-glutamine (Gibco, USA), $100 \mathrm{U} / \mathrm{mL}$ penicillin and $100 \mu \mathrm{g} / \mathrm{mL}$ streptomycin. The insect cell line, Sf9, were-was purchased from IBRC and maintained in serum-free medium SF-900 III (Invitrogen, USA) supplemented with $100 \mathrm{U} / \mathrm{mL}$ penicillin and $100 \mu \mathrm{g} / \mathrm{mL}$ streptomycin at $27^{\circ} \mathrm{C}$.

\section{- Construction of recombinant baculoviruses vectors}

Recombinant baculovirus vectors were constructed according to Invitrogen's Bac-to-Bac baculovirus expression system. Briefly, the anti-HER2 scFv was designed according to the amino acid sequences of the variable heavy $\left(\mathrm{V}_{\mathrm{H}}\right)$ and light $\left(\mathrm{V}_{\mathrm{L}}\right)$ regions of trastuzumab containing the 18 amino acids (MEASLAAQAAQIQLVQSG) of the scFvE2/p17 sequence (epitope of the matrix protein (MAp17) of HIV-1) and HA tag (hemagglutinin epitope of Influenza A virus), YPYDVPDYA, in the N and Cterminal- respectively [13]. The vector containing the synthesized anti-HER2 scFv (Genscript (China) was subcloned into the transfer plasmid pFastBac1 (Invitrogen, USA) at BamHI and EcoRI sites to generate anti-HER2 scFv pFastBac1. CMV (cytomegalovirus immediate-early promoter) and the EGFP (the enhanced green fluorescent protein) reporter gene were amplified from vector pEGFP-C1 (BD Biosciences, USA) andUSA) and sub cloned into the anti-HER2 scFv pFastBac1 at SnaBI site and into the plasmid pFastBac1 at BamHI and EcoRI sites to produce the PCMV-EGFP anti-HER2 scFv pFastBac1 and PCMV-EGFP pFastBac1(BV-control); respectively.

To generate a recombinant baculovirus expressing Apoptin, the Apoptin gene was commercially synthesized based on the sequences in GenBank (NC-001427) in pBSK (+) Simple-Amp plasmid by Biomatik (Canada), then the full-length Apoptin gene was amplified by PCR amplification using primers eontacting containing the NheI \& SmaI restriction sites and subcloned into the PCMV-EGFP anti-HER2 scFv pFastBac1 plasmid to create the PCMV-Apoptin anti-HER2 scFv pFastBac1. Subsequently, competent DH10Bac E. coli cells were transformed with the recombinant plasmids 
PCMV-EGFP anti-HER2 scFv pFastBac1, PCMV-Apoptin anti-HER2 scFv pFastBac1, and PCMVEGFP pFastBac1. After selecting colonies through the white/blue selection and PCR with the M13 forward and reverse primers, recombinant bacmids DNA were isolated from white colonies according to the Bbac-to-bac-Bac (Invitrogen) procedure. All primers used for cloning and confirmation showed in the Supplementary Table 1.

\section{- Recombinant Baculovirus production and purification}

For production of recombinant baculoviruses, Sf9 cells were transfected by the recombinant bacmids DNA with CellFectin II reagent (Invitrogen, USA) in 6-well plates at a density of $8 \times 10^{5}$, according to manufacturer's instructions. The supernatant containing recombinant viruses was harvested after 6 days post-transfection and used for large scale viral production. Therefore, Sf9-III cells were infected at $0.01 \mathrm{MOI}$ in T75 flasks and the supernatant was collected at four days post-infection. The recombinant viruses were purified by sucrose gradient ultracentrifugation according to the following protocols.

The supernatants of infected $\mathrm{Sf} 9$ cell culture were harvested at 96 hours post-infection and clarified by centrifugation at $1500 \mathrm{rpm}$ in $4^{\circ} \mathrm{C}$ for $15 \mathrm{~min}$. For electron microscopy, BV particles were further purified by ultracentrifugation at $27000 \mathrm{rpm}$ for 75 minutes at $4^{\circ} \mathrm{C}$ through a $1 \mathrm{ml}$ sucrose cushion (20\% sucrose in PBS) (Beckman Ultracentrifuge). The purified baculoviral pellet was resuspended in PBS overnight at $4^{\circ} \mathrm{C}$ and the titers of $\mathrm{BV}$ suspensions determined by a plaque assay. (Bac-to-Bac Invitrogen)

\section{- Expression of the anti-HER2 scFv in Sf9 cells}

Western blotting was used to confirm the expression of the anti-HER2 scFv protein in Sf9 cells. Sf9 cells were seeded in 6-well plates at a density of $6 \times 10^{5}$ cells per well. After 5 hours, cells were transfected with recombinant baculoviruses at an MOI of 2. Four days later, Sf9 cells were lysed using I-PER Insect cell protein extraction buffer containing protease inhibitor (Thermo Scientific). Cell lysates were centrifuged at $14000 \mathrm{rpm}$ for $10 \mathrm{~min}$ at $4^{\circ} \mathrm{C}$ and protein in the supernatants used for western blotting. Sixty micrograms of each sample, after being heat-denatured for 5 minutes, were loaded into SDS polyacrylamide gel. After migration, proteins were transferred to polyvinylidene difluoride (PVDF) membrane and then treated with an anti-HA mouse monoclonal antibody at a concentration of 1:4000 in 3\% BSA/TBST (Sigma, USA) as primary antibodies. Goat anti-mouse immunoglobulin conjugated to horseradish peroxidase (170-6516, Bio-Rad, USA) diluted 1:5000 in $3 \%$ BSA/TBST was used as the secondary antibody for detection of the primary antibodies. The protein bands were detected with via ECL (Cyto Matin Gene, Iran) according to the manufacturer's guidelines.

\section{- Indirect ELISA}

The functionality of recombinant anti-HER2 $\mathrm{scFv}$ was evaluated by their binding activity to the recombinant extracellular region of HER2 (HER2-ECD) antigen [25] (SinaBiotech Co, Tehran, Iran), invia a standard indirect ELISA procedure. In brief, $50 \mu \mathrm{l}$ of recombinant HER2-ECD antigen solution at $2 \mu \mathrm{g} / \mathrm{ml}$ in PBS buffer ( $\mathrm{pH} 7.5$ ) were was incubated overnight at $4^{\circ} \mathrm{C}$ in 96 -well plates. The coated wells were blocked with $50 \mu$ of blocking buffer (1\% BSA in PBS) for 1.5 hours $h$ and a half at $37^{\circ} \mathrm{C}$, then washed three times with washing buffer (0.05\% Tween-20 in PBS). $50 \mu$ l of purified anti-HER2 scFv-BV and EGFP-BV at dilutions of 1:1000 were added to each well and incubated for $1 \mathrm{hr}$ at $37^{\circ} \mathrm{C}$. After three times of washing, monoclonal anti-HA tag antibody (Sigma, USA) was 
added at a dilution of 1:2000 in 1\% BSA-PBS, and incubated for $1 \mathrm{hr} 37^{\circ} \mathrm{C}$. After three washes, wells were further incubated with $50 \mu \mathrm{l}$ of Goat anti-mouse antibody conjugated to HRP (Bio-Rad, USA) diluted 1:3000 in $1 \%$ BSA-PBS and incubated for $1 \mathrm{hr} 37^{\circ} \mathrm{C}$. Then $50 \mu \mathrm{l}$ of TMB solution was added to each well. Finally, the reaction was stopped by addition of $50 \mu \mathrm{l}$ of $10 \%$ sulfuric acid and the absorbance measured by using an ELISA plate reader at $450 \mathrm{~nm}$.

\section{- Sandwich ELISA}

The binding specificity of the anti-HER2 scFv expressing on the surface of recombinant baculovirus was determined by a sandwich ELISA. $50 \mu \mathrm{l}$ of purified BV-PCMV-EGFP anti-HER2 scFv and BVcontrol at dilutions of 1:1000 in carbonate buffer ( $\mathrm{pH} 9.6$ ), were added to each well and incubated overnight at $4{ }^{\circ} \mathrm{C}$ in 96 -well plates. The coated wells were blocked with $50 \mu 1$ of blocking buffer $(1 \%$ BSA in PBS) for 1.5 hours at $37{ }^{\circ} \mathrm{C}$ and washed three times with washing buffer $(0.05 \%$ Tween- 20 in PBS). Then $50 \mu \mathrm{l}$ of recombinant HER2-ECD antigen solution at $2 \mu \mathrm{g} / \mathrm{ml}$ in PBS added to each well and incubated for $1 \mathrm{hr}$ at $37{ }^{\circ} \mathrm{C}$. After washing the wells, $50 \mu \mathrm{l}$ of HRP conjugated anti-HER2 monoclonal antibody (1T0 mAb), which recognizes different epitopes to trastuzumab [26], was added to each well and incubated for $1 \mathrm{hr}$ at $37{ }^{\circ} \mathrm{C}$. Following a final wash, TMB substrate was added to each well and absorbance read at $450 \mathrm{~nm}$.

\section{- Indirect Immunofluorescence Assay}

To confirm the expression of anti-HER2 scFv protein an indirect immunofluorescence assay was performed. At $72 \mathrm{~h}$ post-infection Sf9 cells were washed with PBS and fixed by methanol/acetone (1:1) for 10 minutes at room temperature (RT), then permeabilized in 5\% Triton X-100 and washed with PBS. The cells were subsequently incubated with the primary antibody anti-HA (1:1000 in 1\% PBSBSA) (Sigma, USA) for 1 hour at $37^{\circ} \mathrm{C}$, followed by three PBS washes and then incubated with the secondary antibody Alexa Fluor 488-conjugated anti-mouse $\operatorname{IgG}$ (1:200 dilution in PBS-BSA) (Abcam, Hong Kong) for 1 hour at $37{ }^{\circ} \mathrm{C}$. After this, wells were washed three times with PBS; followed by three PBS and visualized under fluorescence microscope (Olympus, Japan). We used PBS and BV-control were used as negative controls.

\section{- Electron Microscopy (EM)}

In order to confirm the expression of anti-HER2 $\mathrm{scFv}$ on the surface of the recombinant baculovirus electron microscopy was performed. The carbon-coated grids were covered by $20 \mu 1$ purified baculovirus for 30 minutes. Then grids were incubated with primary antibody anti-HA tag monoclonal antibody at a dilution of 1: 1000 in 1\% PBS-BSA (Sigma, USA) for 1 hour at RT. After washing with PBS three times for 5 minutes, the grids were incubated with $10 \mathrm{~nm}$ gold-tagged goat anti-mouse IgG antibody at a dilution of 1: 100 in 1\% PBS-BSA (Sigma, USA) for 30 minutes at RT in dark. After three PBS washes, the grids were negatively stained with $1 \%$ uranyl acetate in $\mathrm{H} 20$ for 10 min at RT, washed again with PBS, and examined under electron microscopy (LEO 906 Electron microscope (Zeiss, Germany).

\section{- Recombinant baculovirus infection into human breast cancer cell lines}

\section{- Fluorescence microscopy}

Breast cancer cell lines, including SK-BR-3 and MCF-7 were cultured in 6-well plates. For following the specific targeting of HER2-positive breast cancer, cells were infected with recombinant BV carrying PCMV-EGFP anti-HER2 scFv, or BV-control at an indicated MOI for 4 hours at $27^{\circ} \mathrm{C}$. After 
removal of the viruses, fresh medium was added and incubated at $37^{\circ} \mathrm{C} .24,48$, and 72 hours post infection cells were observed using a fluorescence microscopy (Olympus, Japan).

\section{- Assessing Apoptin expression by western blot}

Western blotting was used to confirm the expression of the Apoptin protein. Briefly, SK-BR-3 and MCF-7 breast cancer cells were seeded in 6-well plates at a density of $5 \times 10^{5}$ cells per well. After 24 $\mathrm{h}$, cells were transfected with recombinant BV PCMV-Apoptin anti-HER2 scFv and BV-control at an MOI of 100. Forty eight 48 -hours later, cells were lysed in ice-cold RIPA buffer $(0.1 \%$ SDS, $150 \mathrm{mM}$ $\mathrm{NaCl}, 50 \mathrm{mM}$ Tris- $\mathrm{HCl}, 0.1 \%$ Triton-X100, $0.5 \%$ sodium deoxycholate and protease inhibitor). Cell lysates were centrifuged and protein in the supernatants were used to load into SDS polyacrylamide gel. Rabbit anti-Apoptin (Abcam ab193612; diluted 1:5000 in 3\% BSA/TBST) and mouse anti- $\beta$ Actin (Sigma T5168; diluted 1:2,500 in 3\% BSA/TBST) were used as primary antibodies. HRPconjugated goat anti-rabbit secondary antibody and HRP-conjugated goat anti-mouse secondary antibody (Sigma, USA) were used at 1:6000 dilution. Western blotting was carried out as previously described. Beta-Actin protein was used as endogenous reference. Proteins were detected with the ECL western blotting detection system.

\section{- In vitro cytotoxicity of baculovirus expressing Apoptin in breast cancer cell lines}

Cytotoxicity assessment of the recombinant baculovirus carrying Apoptin (BV-PCMV-Apoptin antiHER2 scFv) earried outwas performed in SK-BR-3 and MCF-7 cells using MTT assays (a tetrazolium dye, 3- [4, 5-dimethylthiazol 2 yl] 2, 5-diphenyltetrazolium bromide; thiazolyl blue). Briefly, SKBR3 and MCF-7 cells were seeded in 96-well plates at a density of $1 \times 10^{4}$ cells and after 24 hours, cells were incubated with the recombinant baculovirus at different MOI (50 and 100), and baculovirus control MOI 100. At 24 and 48 hours post-infection, cell viability was measured by MTT assay kit (BIO-IDEA, Iran) according to the manufacturer's instructions. Three independent experiments were performed and finally, the absorbance at $570 \mathrm{~nm}$ was measured.

\section{- Statistical analysis}

Student's $t$-test was used for statistical analysis. Results were expressed as mean \pm standard deviation (SD), and represent data from three independent experiments. P-value $\leq 0.05, \leq 0.01$ and $\leq 0.001$ were considered significant and are represented by an asterisk $* *_{2}$, and $* * *_{\text {; }}$ respectively.

\section{Results}

\section{- Construction and production of recombinant baculovirus}

To construct recombinant baculovirus vectors according to the Bac-to-Bac Invitrogen technology, the anti-HER2 scFv containing the 18 amino acids (MEASLAAQAAQIQLVQSG) sequence in the Nterminal for displaying the anti-HER2 scFv on the BV's envelope, and containing an HA tag at the Cterminal to detect the expressed protein by HA-tag monoclonal antibody in western blotting and immunofluorescence, were cloned into the plasmid pFastBac1. Then CMV promoter and EGFP were amplified from the vector pEGFP-C1 and sub-cloned into the anti-HER2 scFv pFastBac1 and into the plasmid pFastBac1 to produce the PCMV-EGFP anti-HER2 scFv pFastBac1 and PCMV-EGFP pFastBac1; respectively. PCMV-EGFP anti-HER2 scFv pFastBac1 were transfected into $\mathrm{CHO}$ and HEK-293 cell lines to confirm the EGFP expression (Supplementary Figure 1a, b). 
To generate a recombinant baculovirus expressing Apoptin, the Apoptin gene was subcloned into the PCMV-EGFP anti-HER2 $\mathrm{scFv}$ pFastBac1 plasmid which was constructed in the previous process to create the PCMV-Apoptin anti-HER2 scFv pFastBac1. The structures of the engineered recombinant BVs in this study are shown in Figure $1(\mathrm{~A}-\mathrm{C})$. Subsequently, competent DH10Bac E. coli cells were transformed with the recombinant pFastBaclplasmids to produce the recombinant bacmids. After selecting colonies through the white/blue selection, the production of recombinant bacmids DNA was confirmed by PCR with the M13 forward and reverse primers (Supplementary Figure 2).

In order to produce the recombinant baculoviruses, Sf9 cells were transfected by the recombinant bacmids. The viral particles were produced in Sf9 cells at 96 hours post-transfection, CPE in transfected Sf 9 cells was confirmed by observation ofby increasing increased in-size and rounding up was observed in the transfected cells (Figure 1D) compared to the controls (Figure 1E). The recombinant viruses were purified by sucrose gradient ultracentrifugation and the titers of BV suspensions were determined by plaque assay. The titers of the purified viruses were $1.6 \times 10^{7}$ $\mathrm{PFU} / \mathrm{ml}$ for $\mathrm{BV}$-control, $1.8 \times 10^{8} \mathrm{PFU} / \mathrm{ml}$ for BV-PCMV-EGFP anti-HER2 $\mathrm{scFV}$ and $1.5 \times 10^{7}$ $\mathrm{PFU} / \mathrm{ml}$ for BV- PCMV-Apoptin anti-HER2 scFv.

\section{- Expression of anti-HER2 scFv in Sf9 cells}

The expression of the anti-HER2 scFv in Sf9 cells was confirmed by western blotting analysis using mouse anti-HA-tag monoclonal antibody and horseradish peroxidase labelled goat anti-mouse IgG. The results showed that anti-HER2 scFv protein with a molecular weight of $30 \mathrm{kDa}$ was expressed by recombinant BV-PCMV-EGFP anti-HER2 $\mathrm{scFv}$ and BV- PCMV-Apoptin anti-HER2 scFv in transfected cells but not in BV-Control and non-transfected Sf9 cells after 96 hours post--infection (Figure 2).

\section{- Immunological functionality and specificity of anti-HER2 scFv displayed on the baculovirus envelope}

Efficient display of functional anti-HER 2 scFv on the BV surface was confirmed by Indirect ELISA using a recombinant extracellular region of HER2 (HER2-ECD) antigen. In this assay, recombinant HER2-ECD antigen was coated in the wells of the plate, then purified BV virions was-were added to each well and probed with monoclonal anti-HA tag antibody. The positive reaction indicated significanttly the binding of a specific epitope of the HER2-ECD antigen to the anti-HER2 scFv displayed on the baculovirus envelope ( $\mathrm{p}$-value $=-0.0015)$ and also confirmsed that the c-terminal region of anti-HER $2 \mathrm{scFv}$ was exposed at the surface of the BV. No binding of antibodies to controls were observed. (Figure 3A)

The Sandwich ELISA $\underline{s}$ were designed to assess the binding specificity and accessibility of anti-HER2 $\mathrm{scFv}$ antigen-binding regions. BV-PCMV-EGFP anti-HER2 $\mathrm{scFv}$ and $\mathrm{BV}$ control virions were immobilized on an ELISA plate and incubated with recombinant HER2-ECD antigen, then probed with HRP--conjugated anti-HER2 monoclonal antibody which recognize different epitopes than trastuzumab. The result shows that BV-PCMV-EGFP anti-HER2 $\mathrm{scFv}$ significantly reacted with recombinant HER2-ECD antigen in compare withcompared to controls (p-value 0.02) (Figure 3B).

\section{- Indirect Immunofluorescence analysis of BV- displayed anti-HER2 scFv}

BV-infected Sf9 cells were harvested at 72 hours post_-infection and examined in via immunofluorescence microscopy using anti-HA tag antibody. Immunofluorescence analysis of the 
BV-displayed anti-HER2 scFv showed that anti-HER2 scFv expressed on the BV and the C-terminal HA tag was oriented outwards (Figure 4A) in compare withcompared to the negative controls of PBS and BV-control as a negative control (Figure 4B, 4C).

\section{- Immuno-Electron Microscopy of baculovirus displaying anti-HER2 scFv}

In order to confirm the reality of surface expression of anti-HER2 $\mathrm{scFv}$ on the recombinant baculovirus, the carbon-coated grids were covered by purified baculovirus and incubated with immune gold-labelled anti-HA tag antibody-, observed under the electron microscope. The result demonstrated that gold particles attached to the surface of recombinant BV-displayed anti-HER2 scFv (Figure 5A). In contrast, no gold anti-HA labelling were detected on the surface of BV-control virions (Figure 5C5B).

\section{- Selective targeting of BV-displaying anti-HER2 SCFv-selectively targets the HER2 positive} SK-BR-3 breast cancer cells

The targeting property properties of BV-displaying anti-HER2 scFv against HER2-positive breast cancer cells were determined by evaluating EGFP expression under the fluorescence microscopy using the human breast cancer cell lines SK-BR-3 and MCF-7 which exhibit high and low HER-2 expression, respectively_(25). Breast cancer cells were infected with recombinant BV-PCMV-EGFP anti-HER2 scFv at different MOIs 50,100,200, and BV-control at MOI 100 at 24, 48, and 72 hours post-infection.

As shown in Figure 6 BV-displaying anti-HER2 $\mathrm{scFv}$ could specifically bind to SK-BR-3 cells and expressed EGFP in a dose--dependent manner in compared withcompared to no fluorescence detection on BV-Control and MCF-7 cell lines.

\section{- Apoptin expression in breast cancer cells of determined by western blot}

Western blot analysis was performed to determine whether the Apoptin protein was expressed in the SK-BR-3 and MCF-7 breast cancer cells after infection with recombinant BV-PCMV-Apoptin antiHER2 scFv at an MOI of 100 at 48 hours post-infection. As shown in Figure 7, a band corresponding to a molecular weight of about approximately $40 \mathrm{kDa}$ was detected in the cell lysates of BV-PCMVApoptin anti-HER2 scFv transduced cells but not in the cell lysates of BV-control transduced cells. The results demonstrated low level of Apoptin expression in MCF-7 cell line in compared with SKBR-3 cell lines ( $\mathrm{p}$-value $=-0.00017)$.

\section{- BV-displaying anti-HER2 scFv Apoptin cytotoxicity is selectively cytotexic to SK-BR-3 HER-2 positive breast cancer cells}

Cytotoxic effects of BV anti-HER2 scFv expressing Apoptin, in SK-BR-3 and MCF-7 breast cancer cell lines was measured by MTT assays. The results showed that BV anti-HER2 scFv expressing Apoptin significantly reduced the cell viability of SK-BR-3 HER-2 positive breast cancer cell lines in compare withcompared to MCF-7 cells at 24 and 48 hours post--infection (Pp-value 0.016 and 0.006 ; respectively) at an MOI 50 in a time-dependent manner. In addition, BV anti-HER2 scFv expressing Apoptin decreased the cell viability of SK-BR-3 cell lines $20.6 \%$ and $25.3 \%$ in compare with compared to MCF-7 cells at 24 and 48 hours post-infection at an MOI 100. In contrast, when cells were treated with BV anti-HER2 scFv and BV-Control there was no significant difference in the cell viability of the MCF-7 and SK-BR-3 cells. These data indicated that BV anti-HER2 scFv expressing 
Apoptin specifically killed SK-BR-3 HER-2 breast cancer cells while it had low or no toxicity in MCF-7 breast cancer cells. (Figure 8A, 8B)._All samples normalizes with BV controls.

\section{Discussion}

Targeted cancer therapy is becoming important due to its specificity towards cancer cells whereas whilst leaving normal cells intact [27]. Since HER2 targeted therapies have shown indisputable clinical benefit in metastatic breast cancer [28], we generated a recombinant baculovirus displaying anti-HER2 scFv expressing cytotoxic protein Apoptin was generated. We demenstrated that our This recombinant BV is able to selectively target the HER2 positive breast cancer cell line SK-BR-3 (Figure- 6 ) and reduced its cell viability by expressing Apoptin (Figure: 8A,BA, B) but not in the HER2 negative MCF-7 breast cancer cell line.

Baculovirus display technology previously showed that has advantages in the target therapy applicationhas previously been shown to have been employed with regard to targeted cancer therapy. Baculovirus vector displaying scFv-CEA (Carcino Embryonic Antigen) fusion to GP64 showed a binding specificity to CEA-expressing cells [29]. Different strategies for the fusion of a foreign protein or peptide to the baculovirus envelope, including fusion to GP64 and VSV-G glycoprotein, hasve been proposed [13]. In order to conquer the limitation of these strategies which restrict the display to the poles of the virions, Kitidee et aland colleagues demonstrated that fusion of an octadecapeptide sequence N18E2 (MEASLAAQAAQIQLVQSG), which mediates the anchoring of $\mathrm{scFv}$ into the baculoviral envelope, to the $\mathrm{N}$-terminus of $\mathrm{scFv}$ molecules of interest could be applied for BV display [13].

In our - this study, - _ we used the N18E2 sequence was used, 18 amino acids (MEASLAAQAAQIQLVQSG) sequence in the N- terminus of anti-HER2 $\mathrm{scFv}$ for displaying the $\underline{\mathrm{scFv}}$ on the BV's envelope. As shown in the fig Figure $5 \mathrm{~A}$ gold particles attached to the surface of recombinant BV-displayed anti-HER2 scFv. Our findings in corroborate with the findings by Kitidee et aland colleagues resultswhich demonstrated that this strategy can be used for displaying the scFv on the surface of BV [13]. Moreover, immunofluorescence analysis showed that anti-HER2 scFv was expressed on the recombinant BV in comparewhislt no such expression was seen with PBS and BVcontrol (Figure 4), consistent with in corroborate with electron microscopy results (Figure 5). Binding specificity and efficient display of anti-HER2 $\mathrm{scFv}$ on the BV surface was confirmed by ELISA (Figure 3A, 3-B). These data suggested-indicated proper display of that anti-HER2 scFv-properly displayed on the BV surface.

Gene therapy has become an attractive strategy for the cancer treatment in recent years, with the use of . Whereas baculoviruses has demonstrating several potential advantages over other vectors in this field-[30]. For the first time, Hofmann and colleagues demonstrated that the baculovirus has the ability as a vector to deliver sustainable foreign genes expression in human hepatocytes in 1995 [31]. Since then, BV has shown to be capable of transducing a wide range of mammalian cells and has been used as a gene therapy vector in a preclinical studies [32-35].

In the current study, we demonstratedit was demonstrated that BV-displaying anti-HER2 scFv could specifically bind to HER2-overexpressing SK-BR-3 cells but not to the HER2 negative MCF-7 cells (Figure 6). In addition, eur the results showed that this targeting activity is in a dose--dependent manner and abundant expression of GFP at an MOI 200 after transduction with BV- anti-HER2 scFv confirmed the targeting of HER2--positive breast cancer cells (Figure 6). This finding is in accordance with reports that from $\mathrm{Li}$ et aland colleagues in 2001. They demonstrated that a non-viral vector carrying anti-ErbB2 scFv (ScFv-P-S) ean-selectively targeteds the ErbB2(+) cells with an 8 to 10 fold increase in luciferase reporter gene expression levels in compared withcompared to ErbB2(-) cells [36]. In another study, Zhao and his colleagues generated the expression vector pCMV-e23sFv-PE II 
GrBa which was able to selectively identifyfied and destroyed SKBR-3 cells which expressed higher levels of HER2 [37].

Other works have used anti-HER2 scFv antibody for targeting breast cancer cells using the Pichia pastoris as the host for the expression of antibody fragments [38] and developing anti-HER2 scFvHSA fusion antibodies conjugates with drug DM1 [39]. In a recent study, Alric and colleagues showed the specific binding and high affinity properties of SPIONs-Cy-PEG-ScFv nanoparticles against HER2 positive breast cancer cells, leading to Alric and colleagues and suggestingsuggesting the use of this nanoparticle as an imaging agent for the diagnosis of breast tumors with HER2 overexpression [40]. ThereforeTherefore, novel therapeutic approaches which facilitate the selective targeting of breast cancer cells such as using viral vector displaying anti-HER2 scFv will be considered as a promising candidate for delivering genes to HER2 positive breast cancer cells.

However, Apoptin has been shown to be able to induce the-apoptosis in a variety of tumor cells [18], [18] and efficient delivery systems is -are required to transfer Apoptin to cancer cells. Here we showed that the ability of BV-displaying anti-HER2 scFv to deliver Apoptin into breast cancer cells was demonstrated (Figure 7). Our The findings presented herein indicated that Apoptin protein was highly expressed in the SK-BR-3 HER2 positive breast cancer cell line. The lLow level of Apoptin expression in MCF-7 cells line may be explained by the low level of HER2 receptor at the MCF-7 cells. This finding is in consistent with Alric and colleagues which showed $99 \%$ of SK-BR-3 cells highly expressed the HER2 receptors at the cell surface in compare withcompared to $26 \%$ of MCF-7 cells. They also demonstrated that the uptake of nanoparticle SPIONs-Cy-PEG-scFv by breast cancer cells is related to level of HER2 expression. According to their finding the amount of SPIONs-CyPEG-scFv able to penetrate the MCF-7 cells (considered as a HER2 negative) is very few in compared withcompared to high uptake in SK-BR-3 HER2 positive cell lines [40].

To assess the cytotoxic effect of BV anti-HER2 scFv expressing Apoptin, SK-BR-3 and MCF-7 cells were treated with this vector. As shown in Figure 8A-8-B the viability of SK-BR-3 breast cancer cells treated with BV anti-HER2 scFv expressing Apoptin significantly has reduced compared to MCF-7 cells. Consistent with our these results Pan and colleagues developed a recombinant baculovirus expressing Apoptin and showed its antitumor effects in transduced HepG2 and H22 cells [9]. Several studies reported an antitumor effect of Apoptin in breast cancer cells. Shoae-Hassani and colleagues constructed a $\lambda$ phage expressing the-Apoptin which significantly inhibited growth of the-various breast cancer cell lines in vitro [18]. AnoOther study also showed that HSA--mediated Apoptin infection was able to reduce the viability and induce the apoptosis in $\mathrm{MCF}_{-}-7$ cells [41]. In addition, our the results presented herein demonstrated that that BV anti-HER2 $\mathrm{scFv}$ expressing Apoptin specifically killed SK-BR-3 HER-2 breast cancer cells, while-whilst it had low or no toxicity in MCF7 breast cancer cells.

\section{Conclusions}

The present study is the first effort for targeting HER2--positive breast cancer cells by anti-HER2 scFv BV expressing Apoptin. Our This recombinant baculoviruseonstruct resulted in the successful targeting of HER2-overexpressing SK-BR-3 cells. Furthermore, eur-the results showed that the viability of SK-BR-3 breast cancer cells treated with BV anti-HER2 $\mathrm{scFv}$ expressing Apoptin significantly has reducedwas significantly reduced compared to MCF-7 cells. Our-The results suggest that- anti-tumor effect of Apoptin in combination with HER2 targeting of this recombinant BV makes it a promising vector not only in breast cancer therapy but also in other HER2 over-expressing tumors [42].

The result of this study provides new insight into breast cancer target therapy. Further studies are needed with more breast cancer cell lines to reveal selective targeting of BV anti-HER2 scFv expressing Apoptin in HER2 positive cells. Also, in vivo studies need to be done to assess the inhibition of tumor growth without affecting the normal tissue. 
The result of the present study shows that a combination of the anti-HER2 scFv targeting property with the cytotoxic effector Apoptin, is an applied approach for the treatment of HER2-positive breast tumors. In the first stage, this recombinant baculovirus showed the promising results in in vitro study. In the next stage, assessing the specific tumor-targeting property of this recombinant BV in normal human breast cells beside the other breast cancer cell lines is very useful. If this vector passes the preclinical animal studies, it could be employed in the clinical trial study.

\section{Financial \& competing interest's disclosure}

This research was part of a $\mathrm{PhD}$ thesis supported by Tehran University of Medical Sciences and health services (grant no. 94-02-27-29282). The authors declare that they have no conflict of interest in the research.

\section{Summary points}

\section{EXECUTIVE SUMMARY}

Aim

- Targeted cancer therapy is becoming important due to its specificity towards cancer cells whereas whilst leaving normal cells intact

- This study aimed to generate a recombinant baculovirus displaying anti-HER2 scFv expressing Apoptin and we evaluatede its binding specificity and cytotoxicity to HER2-overexpressing SKBR-3 and MCF-7 breast cancer cell lines cells.

Materials \& Methods

- Recombinant baculoviruses were constructed according to the Bac-to-Bac expression system (Invitrogen) and expression of anti-HER2 scFv protein in Sf9 cells were evaluated by western blotting and immunofluorescence microscopy.

- The binding specificity and surface display of anti-HER2 $\mathrm{scFv}$ was evaluated by ELISA and electron microscopy- respectively.

- Targeting propertiesy of BV-displaying anti-HER2 scFv against HER2 positive-SK-BR-3 breast cancer cells was determined by evaluating EGFP expression under the fluorescence microscopy.

- Apoptin expression and its cytotoxic effect was evaluated in in SK-BR-3 and MCF-7 cells by western blotting and MTT assay.

Formatted: Font: (Default) Times New Roman, 12 pt, Highlight

Formatted: Font: (Default) Times New Roman, 12 pt 
- BV-displaying anti-HER2 scFv could specifically bind to HER2-overexpressing SK-BR-3 cells but not to the HER2 negative MCF-7 cells which have low HER2 expression.

- The viability of SK-BR-3 breast cancer cells treated with BV anti-HER2 scFv expressing Apoptin significantly has reducedwas significantly reduced compared to MCF-7 cells.

- These results suggest that the anti-tumor effect of Apoptin in combination with HER2 targeting of this recombinant BV makes it a promising vector in targeted cancer therapy in HER2 over expressing tumors.

\section{References}

\section{Papers of special note have been highlighted as:}

- of interest

1. Shayestehpour M, Moghim S, Salimi V et al. Selective replication of miR-145-regulated oncolytic adenovirus in MCF-7 breast cancer cells. Future Virology 11(10), 671-680 (2016).

2. Shayestehpour M, Moghim S, Salimi $V$ et al. Targeting human breast cancer cells by an oncolytic adenovirus using microRNA-targeting strategy. Virus research 240 207-214 (2017).

3. Friese CR, Harrison JM, Janz NK et al. Treatment - associated toxicities reported by patients with early - stage invasive breast cancer. Cancer 123(11), 1925-1934 (2017).

4. Cheraghi R, Nazari M, Alipour M, Majidi A, Hosseinkhani S. Development of a Targeted antiHER2 SCFv chimeric peptide for gene delivery into HER2-positive breast cancer cells. International journal of pharmaceutics 515(1), 632-643 (2016).

5. Cao X, Yu H, Chen C, Wei J, Wang P. Expression and characterization of recombinant humanized anti-HER2 single-chain antibody in Pichia pastoris for targeted cancer therapy. Biotechnology letters 37(7), 1347-1354 (2015).

6. Nika L, Wallner J, Palmberger D, Koczka K, Vorauer-Uhl K, Grabherr R. Expression of fulllength HER2 protein in Sf9 insect cells and its presentation on the surface of budded viruslike particles. Protein expression and purification 136 27-38 (2017).

7. Kwang TW, Zeng X, Wang S. Manufacturing of AcMNPV baculovirus vectors to enable gene therapy trials. Molecular Therapy-Methods \& Clinical Development 3 (2016).

8. Guo H, Choudhury $\mathrm{Y}$, Yang J et al. Antiglioma effects of combined use of a baculovirual vector expressing wild - type p53 and sodium butyrate. The journal of gene medicine 13(1), 26-36 (2011).

9. Pan $\mathrm{Y}$, Fang L, Fan $\mathrm{H}$ et al. Antitumor effects of a recombinant pseudotype baculovirus expressing Apoptin in vitro and in vivo. International journal of cancer 126(11), 2741-2751 (2010).

10. Ge J, Liu Y, Jin L, Gao D, Bai C, Ping W. Construction of recombinant baculovirus vaccines for Newcastle disease virus and an assessment of their immunogenicity. Journal of biotechnology 231 201-211 (2016).

11. Ge J, An $\mathrm{Q}$, Gao D, Liu $\mathrm{Y}$, Ping W. Construction of recombinant baculoviruses expressing hemagglutinin of $\mathrm{H} 5 \mathrm{~N} 1$ avian influenza and research on the immunogenicity. Scientific reports 624290 (2016).

12. Yan L, Xiangwei $M$, Xiao $L$ et al. Construction, expression and characterization of a dual cancer-specific fusion protein targeting carcinoembryonic antigen in intestinal carcinomas. Protein expression and purification 69(1), 120-125 (2010).

13. Kitidee K, Nangola S, Gonzalez G, Boulanger P, Tayapiwatana C, Hong S-S. Baculovirus display of single chain antibody (scFv) using a novel signal peptide. BMC biotechnology 10(1), 80 (2010). 
14. Amiri SA, Shahhosseini $\mathrm{S}$, Zarei $\mathrm{N}$ et al. A novel anti-CD22 scFv-apoptin fusion protein induces apoptosis in malignant B-cells. AMB express 7(1), 112 (2017).

15. Nejatollahi F, Jaberipour M, Asgharpour M. Triple blockade of HER2 by a cocktail of antiHER2 scFv antibodies induces high antiproliferative effects in breast cancer cells. Tumor Biology 35(8), 7887-7895 (2014).

16. Safdari Y, Ahmadzadeh V, Khalili M, Jaliani HZ, Zarei V, Erfani-Moghadam V. Use of singlechain antibody derivatives for targeted drug delivery. Molecular Medicine 22258 (2016).

17. Shan L-Q, Qiu X-C, Xu Y-M et al. scFv-mediated delivery of truncated BID suppresses HER2positive osteosarcoma growth and metastasis. Cancer biology \& therapy $7(11), 1717-1722$ (2008).

18. Shoae-Hassani A, Keyhanvar $\mathrm{P}$, Seifalian $\mathrm{AM}$ et al. $\lambda$ Phage nanobioparticle expressing apoptin efficiently suppress human breast carcinoma tumor growth in vivo. PloS one 8(11), e79907 (2013).

19. Kuusisto HV, Wagstaff KM, Alvisi G, Jans DA. The C - terminus of apoptin represents a unique tumor cell - enhanced nuclear targeting module. International journal of cancer 123(12), 2965-2969 (2008).

20. Nastasie MS, Thissen H, Jans DA, Wagstaff KM. Enhanced tumour cell nuclear targeting in a tumour progression model. BMC cancer 15(1), 76 (2015).

21. Poon IK, Oro C, Dias MM, Zhang J, Jans DA. Apoptin nuclear accumulation is modulated by a CRM1-recognized nuclear export signal that is active in normal but not in tumor cells. Cancer research 65(16), 7059-7064 (2005).

22. Bae Y, Rhim H-S, Lee S, Ko KS, Han J, Choi JS. Apoptin gene delivery by the functionalized polyamidoamine dendrimer derivatives induces cell death of U87-MG glioblastoma cells. Journal of pharmaceutical sciences 106(6), 1618-1633 (2017).

23. Li X, Jin N, Mi Z et al. Antitumor effects of a recombinant fowlpox virus expressing Apoptin in vivo and in vitro. International journal of cancer 119(12), 2948-2957 (2006).

24. Frithiof $H$, Welinder C, Larsson A-M, Rydén L, Aaltonen K. A novel method for downstream characterization of breast cancer circulating tumor cells following CellSearch isolation. Journal of translational medicine 13(1), 126 (2015).

25. Ghatar RH, Soltantoyeh T, Bahadori T et al. Epitope Mapping of Human HER2 Specific Mouse Monoclonal Antibodies Using Recombinant Extracellular Subdomains. Asian Pacific journal of cancer prevention: APJCP 18(11), 3103 (2017).

26. Amiri MM, Golsaz-Shirazi F, Soltantoyeh $\mathrm{T}$ et al. Hersintuzumab: A novel humanized antiHER2 monoclonal antibody induces potent tumor growth inhibition. Investigational new drugs 36(2), 171-186 (2018).

27. Padma VV. An overview of targeted cancer therapy. BioMedicine 5(4), (2015).

28. Nixon N, Hannouf M, Verma S. A review of the value of human epidermal growth factor receptor 2 (HER2)-targeted therapies in breast cancer. European Journal of Cancer 89 72-81 (2018).

29. Ojala K, Mottershead DG, Suokko A, Oker-Blom C. Specific binding of baculoviruses displaying gp64 fusion proteins to mammalian cells. Biochemical and biophysical research communications 284(3), 777-784 (2001).

30. Swift SL, Rivera GC, Dussupt $V$ et al. Evaluating baculovirus as a vector for human prostate cancer gene therapy. PloS one 8(6), e65557 (2013).

31. Hofmann C, Sandig V, Jennings G, Rudolph M, Schlag P, Strauss M. Efficient gene transfer into human hepatocytes by baculovirus vectors. Proceedings of the National Academy of Sciences 92(22), 10099-10103 (1995).

32. Li Y, Wang X, Guo H, Wang S. Axonal transport of recombinant baculovirus vectors. Molecular Therapy 10(6), 1121-1129 (2004). 
33. Lehtolainen P, Tyynelä K, Kannasto J, Airenne K, Ylä-Herttuala S. Baculoviruses exhibit restricted cell type specificity in rat brain: a comparison of baculovirus-and adenovirusmediated intracerebral gene transfer in vivo. Gene therapy 9(24), 1693 (2002).

34. Tani H, Limn CK, Yap CC et al. In vitro and in vivo gene delivery by recombinant baculoviruses. Journal of virology 77(18), 9799-9808 (2003).

35. Huang W, Tian X-L, Wu Y-L et al. Suppression of gastric cancer growth by baculovirus vectormediated transfer of normal epithelial cell specific-1 gene. World journal of gastroenterology: WJG 14(38), 5810 (2008).

36. Li X, Stuckert P, Bosch I, Marks JD, Marasco WA. Single-chain antibody-mediated gene delivery into ErbB2-positive human breast cancer cells. Cancer gene therapy 8(8), 555 (2001).

37. Zhao J, Zhang L-H, Jia L-T et al. Secreted antibody/granzyme B fusion protein stimulates selective killing of HER2-overexpressing tumor cells. Journal of Biological Chemistry (2004).

38. Sommaruga S, Lombardi A, Salvadè A et al. Highly efficient production of anti-HER2 ScFv antibody variant for targeting breast cancer cells. Applied microbiology and biotechnology 91(3), 613-621 (2011).

39. Zhang $\mathrm{H}$, Wang $\mathrm{Y}, \mathrm{Wu} \mathrm{Y}$ et al. Therapeutic potential of an anti-HER2 single chain antibodyDM1 conjugates for the treatment of HER2-positive cancer. Signal transduction and targeted therapy 217015 (2017).

40. Alric $\mathrm{C}$, Hervé-Aubert $\mathrm{K}$, Aubrey $\mathrm{N}$ et al. Targeting HER2-breast tumors with scFv-decorated bimodal nanoprobes. Journal of nanobiotechnology 16(1), 18 (2018).

41. Wu F, Liu Y, Li J et al. Human serum albumin-mediated apoptin delivery suppresses breast cancer cell growth in vitro and in vivo. Oncology letters 13(2), 579-586 (2017).

42. Yan M, Schwaederle M, Arguello D, Millis SZ, Gatalica Z, Kurzrock R. HER2 expression status in diverse cancers: review of results from 37,992 patients. Cancer and Metastasis Reviews 34(1), 157-164 (2015). 
Figure 1
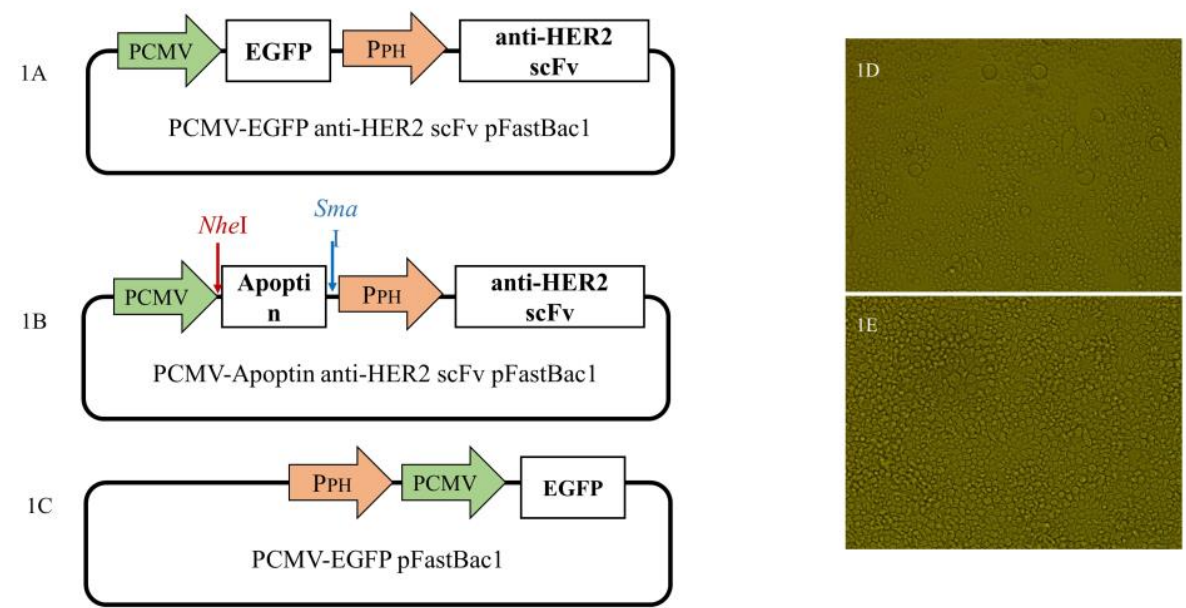
Figure 2

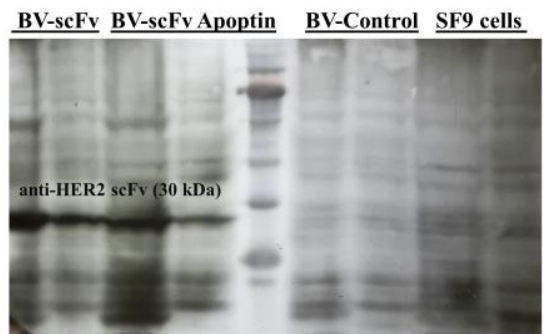


Figure 3

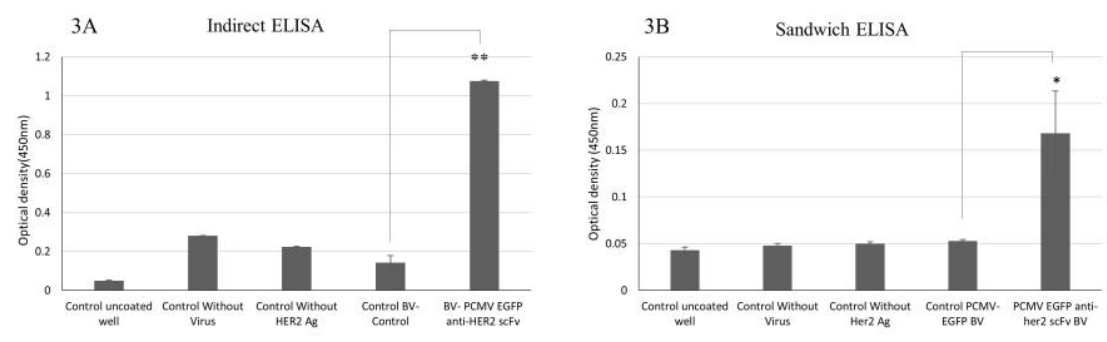


Figure 4

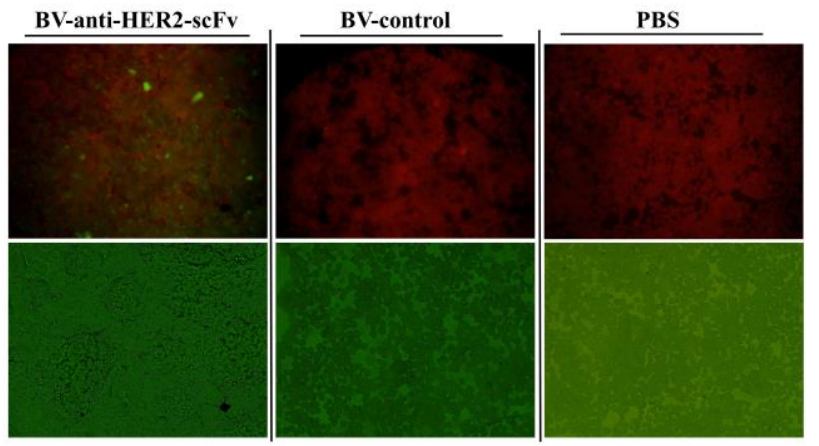


Figure 5

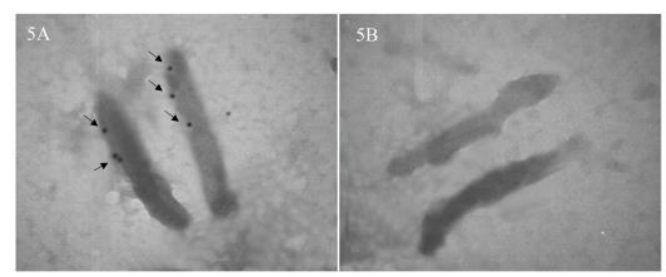


Figure 6

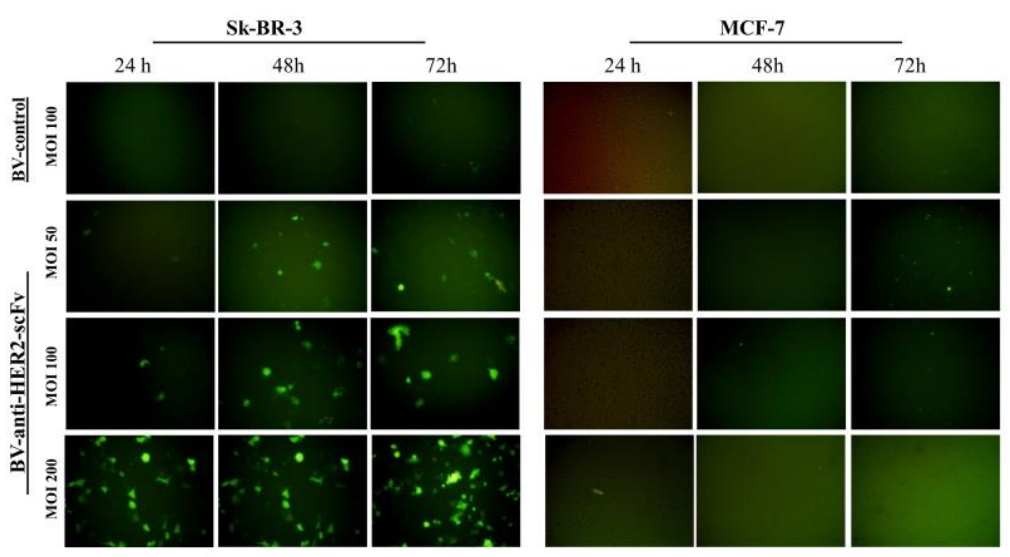


Figure 7

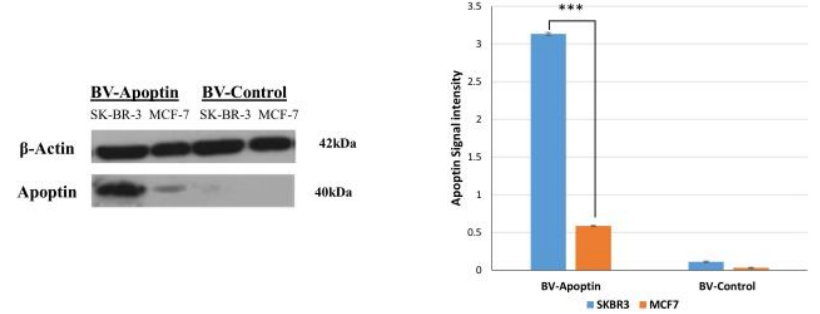


Figure 8
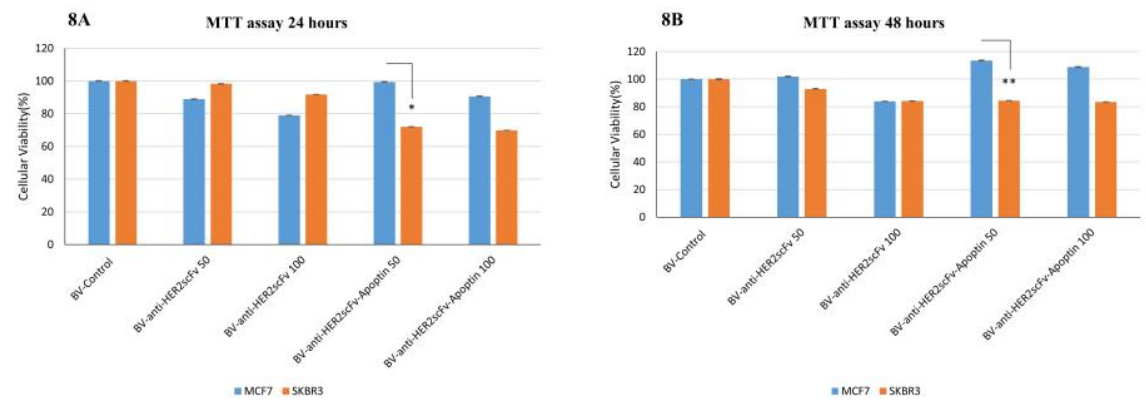
Supplementary Figure 1

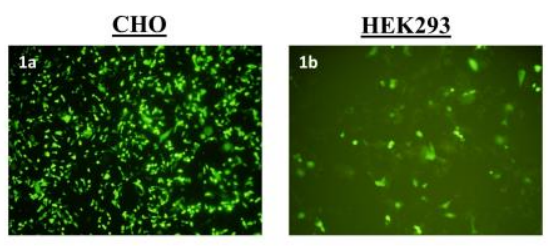


Supplementary Figure 2
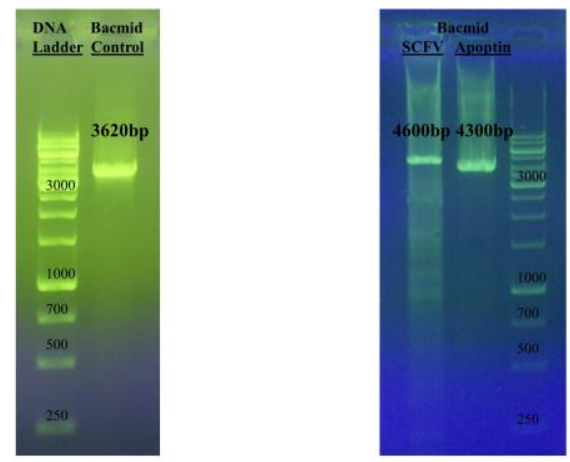


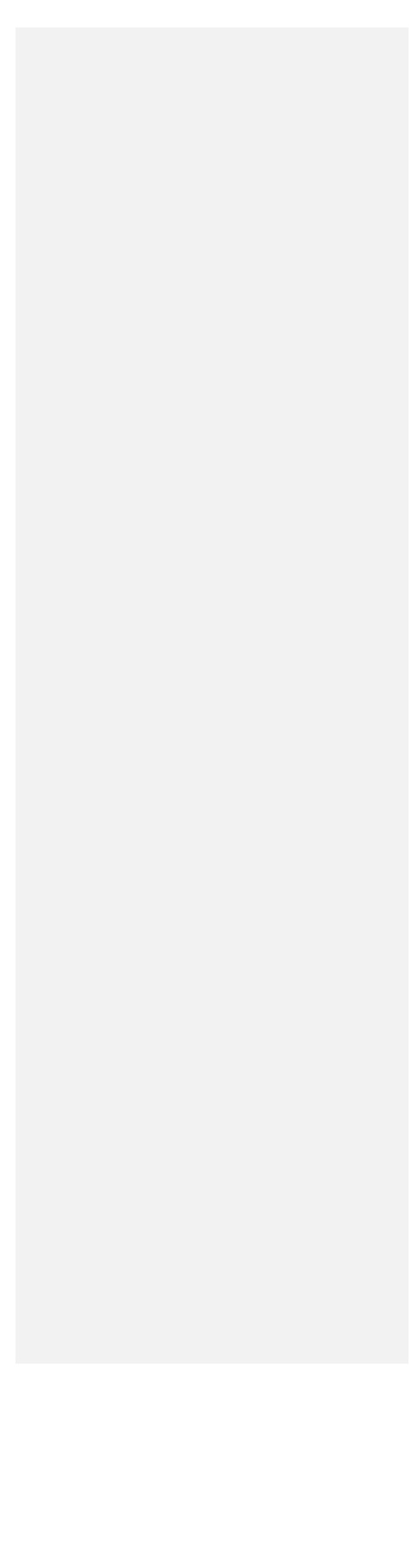




\begin{tabular}{|c|c|c|c|c|}
\hline & Name & Sequence & Direction & $\operatorname{Tm}^{\circ} \mathrm{C}$ \\
\hline \multirow{2}{*}{$\begin{array}{l}\text { anti-HER2 } \\
\text { pFastBac1 }\end{array}$} & PVEC-F & 5'-GCC CAG GAC TCT AGC TAT AGT TCT AGT-3' & Forward & 68 \\
\hline & PVEC-R & 5'-ACT AGA TTT CAC TTA TCT GGT TCG G-3' & Reverse & 63 \\
\hline \multirow[t]{2}{*}{ PCMV-EGFP } & PCMV EGFP-F & 5'-ATAGTAATCAATTACGGGGTCA-3' & Forward & 68 \\
\hline & PCMV EGFP-R & 5'-GCGCGGATCCTTACTTGTACAGCTCGTCC-3' & Reverse & 65 \\
\hline \multirow[t]{2}{*}{ Apoptin } & VP3-F & 5'- AAGCGCTAGCATGAATGCCCTTCA -3' & Forward & 68 \\
\hline & VP3-R & 5'- ACGTCCCGGGTTAAAGTCGTATCCTC -3' & Reverse & 67 \\
\hline \multirow{2}{*}{$\begin{array}{l}\text { Recombinant } \\
\text { BV }\end{array}$} & PUC/M13-F & 5'-CCCAGTCACGACGTTGTAAAACG-3' & Forward & 64 \\
\hline & PUC/M13-R & 5'-AGCGGATAACAATTTCACACAGG-3 & Reverse & 61 \\
\hline
\end{tabular}

